\title{
A MODIFIED CRACK CLOSURE INTEGRAL METHOD FOR CALCULAT- ING STRESS INTENSITY FACTORS FOR CRACKED PLATES SUBJECT TO BENDING LOADS
}

\author{
S.Viswanath, H.V. Lakshminarayana, and D.D.Ravindranath \\ Structures Division, National Aeronautical Laboratory \\ Bangalore-560017, India \\ id: $573341-54$
}

A simple and accurate method is needed for calculating strain energy release rates $(\mathrm{G})$ or the stress intensity factors $(\mathrm{K})$ from the results of finite element analysis of plates with through cracks subjected to bending loads. The purpose of this report is to develop a method to calculate $\mathrm{G}$ or $\mathrm{K}$ using only nodal forces and displacements from a standard finite element analysis code. It is an extension of the well known Modified Crack Closure Integral (MCCI) approach [1-5] to the bending of plates with through cracks. The significant advantages of this method over other methods commonly used to calculate $\mathrm{G}$ or $\mathrm{K}$ are:

1) It avoids dealing with the details of singular stress fields around crack tips, where there are added complexities of anisotropic material behaviour and mode interaction.

2) It permits separation of $\mathrm{G}$ into its components, $\mathrm{G}_{\mathrm{i}}(\mathrm{i}=\mathrm{I}, \mathrm{II}$ and III) in a mixed mode fracture problem.

3) It ensures higher accuracy even with a coarse mesh of conventional elements. Both lower- and higher-order elements can be used.

4. The finite element modeling does not require the use of singular elements at the crack front. However, if singular elements are also used there is a significant improvement in convergence, accuracy, and computational efficiency.

5. The strain energy release rates are calculated directly using crack surface opening displacements and nodal forces at and ahead of crack tips. Therefore computation of element stresses is unnecessary.

6) The method requires only one analysis per crack length. It is not restricted to self-similar crack growth.

7) It can be applied to homogeneous isotropic as well as laminated anisotropic materials.

8) General purpose finite element analysis codes can be used without any modification.

However, application of the MCCI technique to the bending of plates with through cracks has not been reported in the literature.

An examination of bending of plates with through cracks based on shear deformation theories [6-10] revealed that the bending stress intenstity factor $(\mathrm{K})$ depends strongly on the ratio of plate thickness (h) and half crack length (a). Hence, there is a need to examine the effect of (h/a) on the accuracy of $\mathrm{G}$ and $\mathrm{K}$ obtained by the MCCI approach. 
In the present work, the accuracy of the MCCI method is verified by analyzing a square plate of side length $\mathrm{L}$ and thickness $\mathrm{h}$ with a central crack of length 2 a subjected to uniform edge moment $M_{\mathrm{o}}$ and comparing the results with those reported in the literature.

The configuration analyzed is shown in Fig. 1 and a typical finite element model using 4-node quadrilateral plate elements is illustrated in Fig. 2. Exploiting symmetry, only one quarter of the plate has been discretized. Three levels of mesh refinements, where the size of the elements around the crack tip is maintained at $\Delta \mathrm{a} / \mathrm{a}=0.04,0.02$ and 0.01 are considered. The computations were carried out using the CSA/NASTRAN program employing the QUAD4 element The particular element formulation due to Hughes and Tezduyar [11] is based on Mindlin's shear deformation theory and is free from shear locking in the thin limit

For mode I loading, the expression for the strain energy release rate $G_{1}$ is given by

$$
G_{I}=\lim _{\Delta o \rightarrow 0} \frac{1}{2 \Delta a}\left[F_{\theta x}^{i}\left(\theta_{x}^{k}-\theta_{x}^{k^{1}}\right)\right]
$$

Where $F_{\theta x}^{i}$ denotes the nodal force at the crack tip corresponding to the rotational degree of freedom $\theta_{x} ; \theta_{x}^{k}$ is the rotation of the first node $k$ behind the crack front etc., (see Fig. 3). The right hand side of (1) is a function of the nodal forces and displacements calculated from a standad finite element analysis program. Equation (1) can easily be extended to quadratic or cubic element idealisation.

The stress intensity factor $\mathrm{K}$, is calculated from $\mathrm{G}_{1}$ using the relation

$$
K_{I}=\left[\left(G_{l} E h^{3} / 12 \pi\right)\right]^{1 / 2}
$$

The apparent values of $G_{1}$ and hence $K_{I}$ corresponding to the three values of $\Delta \mathrm{a} / \mathrm{a}$ are first obtained. The actual SIF is then obtained by extrapolation to the crack tip.

Table 1 gives the computed values of nondimensionalised bending stress intensity factor

$$
\bar{K}_{J}=K_{3} / \sigma_{0} \sqrt{a}
$$

where $\sigma_{0}=6 \mathrm{M}_{0} / \mathrm{h}^{2}$ for three values of (h/a). The theoretical solution is taken from Hartranft and Sih [12] and the finite element solution is due to Viswanath et al. [10]. The extrapolation to get $\mathrm{K}$ for the three $\mathrm{h} / \mathrm{a}$ ratios is shown in Fig. 4 . It is seen that the prediction by the MCCI approach is excellent for the thickness ratios considered. 
The MCCI approach is then applied to study the effect of decreasing h/a on the accuracy of the computed bending stress intensity factors. Figure 5 the variation $\mathrm{K}_{1}$ with $\mathrm{h} / \mathrm{a}$. The results obtained by the MCCI approach are as open circles along with the theoretical solution of Hartranft and $\operatorname{Sin}[12]$ as a continuous curve. The singular element solution is due to Viswanath et al. [10]. It is seen that the predictions from MCCI approach start deviating considerably for $\mathrm{fc} / \mathrm{K}<0.35$. For instance the error is of the order of 15 percent for $h / a=0.1$. Obviously a further refinement of the adopted finite element mesh to be necessary for $\mathrm{h} / \mathrm{a}<0.35$. Alternatively it is useful to experiment with quadratic or cubic elements.

Thus, this report demonstrates that the MCCI approach is simple to apply, ensures high accuracy with a coarse mesh and does not require the use of singular elements. Obviously, much work remains to be done to establish the accuracy of the MCCI approach for mode II and mixed mode loading conditions.

This study also sets the stage for confident application of the MCCI approach for the solution of crack problems in general shell structures.

\section{REFERENCES}

[1] E.F. Rybicki and M.F. Kanninen, Engineering Fracture Mechanics 9 (1977) 931-938.

[23 F.G. Buchholz, ART in FEM Technology, Robinson and Associates (1984).

[3] T.S. Ramamurthy et al., Mechanics Research Communications 13 (1986) $179-186$.

[4] I.S. Raju, Engineering Fracture Mechanics 28 (1987) 251-274.

[5]K.N. Shivakumar, P.W.Tan, and J.C.Newman, Jr., International Journal of Fracture 36 (1988) R43-R50.

[6] K. Moriya, in Proceedings 23rd Japan Congress for Materials Research (1979) 68.

[7] M.V.V. Murthy, K.N. Raju, and S. Viswanath, International Journal of Fracture 17(1981) 537-552.

[83 G. Yagawa and T. Nishioka, International Journal of Numerical Methodsin Engineering 14(1979) 727-740.

[9] H.C.Rhee and S.N. Athuri, International Journal of Numerical Methods in Engineering 18 (1982) 259-271.

[10] S. Viswanath, M.V.V. Murthy, A.V. Krishna Murthy, and K.P. Rao, Engineering Fracture Mechanics, to appear.

[11] T.J.R. Hughes and T.E. Tezduyar, Journal ofApplied Mechanics 48 (1981) $587-596$.

f12] R.J. Hartranft and G.C. Sih, Journal ofMathematics and Physics 47 (1968) 276-291. 
Table - 1

Nondimensionalized SIF $\left(\bar{K}_{I}=K_{I} / \sigma_{b} \sqrt{a}\right)$ in a square plate with a central crack siubjected to an edge moment $M_{0}$ * $\sigma_{0}=6 M_{0} / h^{2} ; v=0.25$

$\begin{array}{cccc}\text { h/a } & \begin{array}{c}\text { Present } \\ \text { solution }\end{array} & \text { FEM solution } & \text { Theoretical } \\ & {[10]} & {[12 !}\end{array}$
$0,6325 \cdot 0.7000$
0.7014
0.7060
1.5810. 0.7833
0.7833
0.7860
3.1620
0.8666
0.8642
0.8680

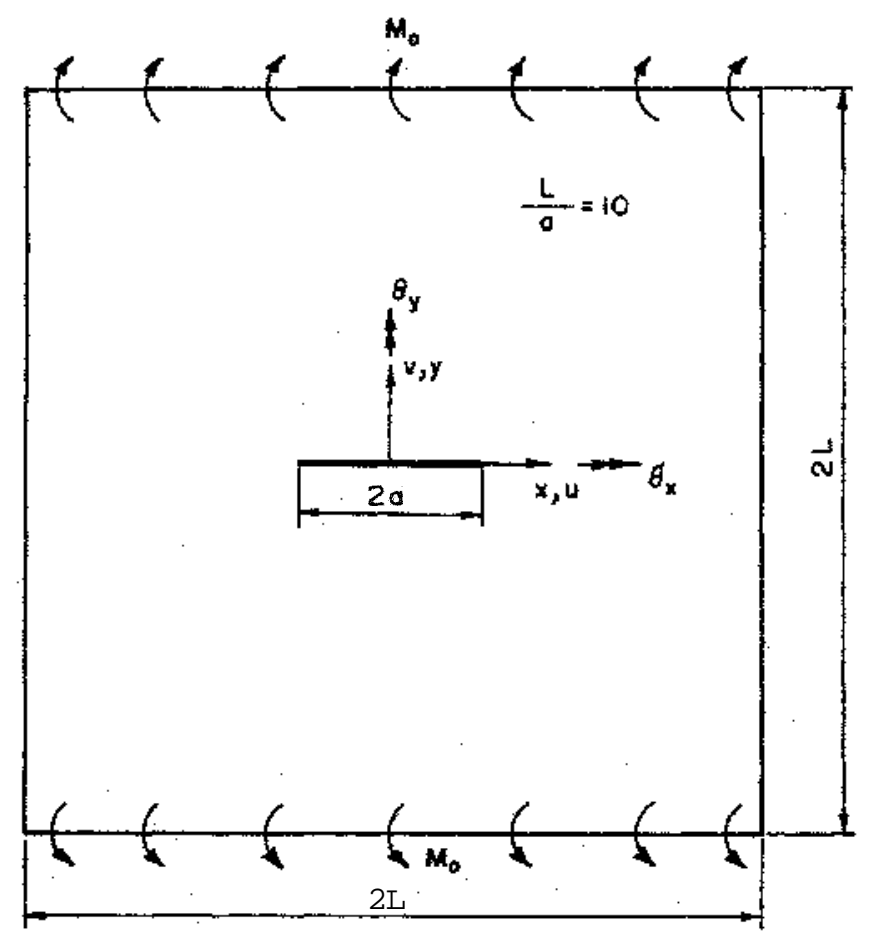

Figure 1. A square plate with a central crack subjected to uniform edge acrent. 

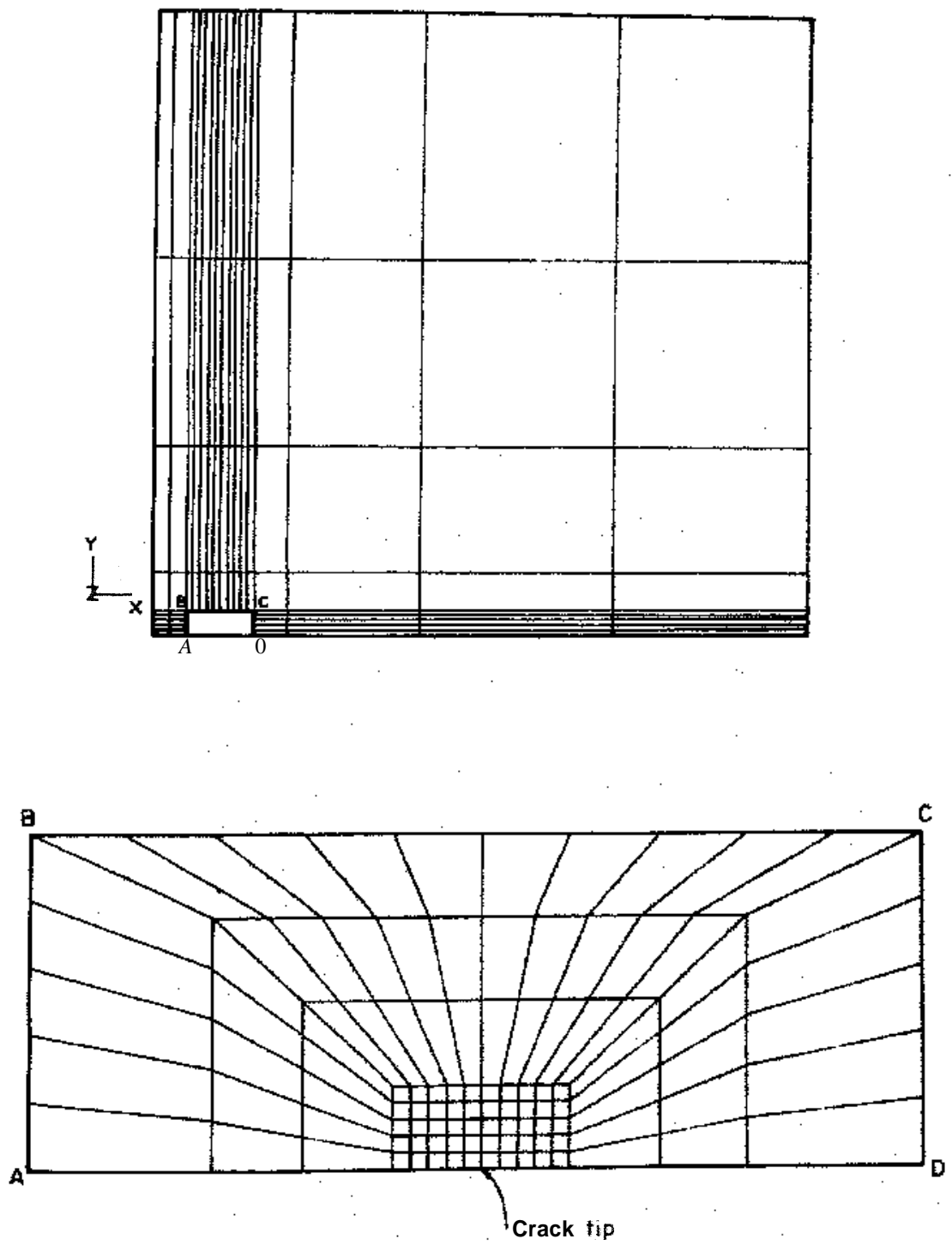

Figure 2. Finite element discretization of a square plate with a central crack (quarter plate). 


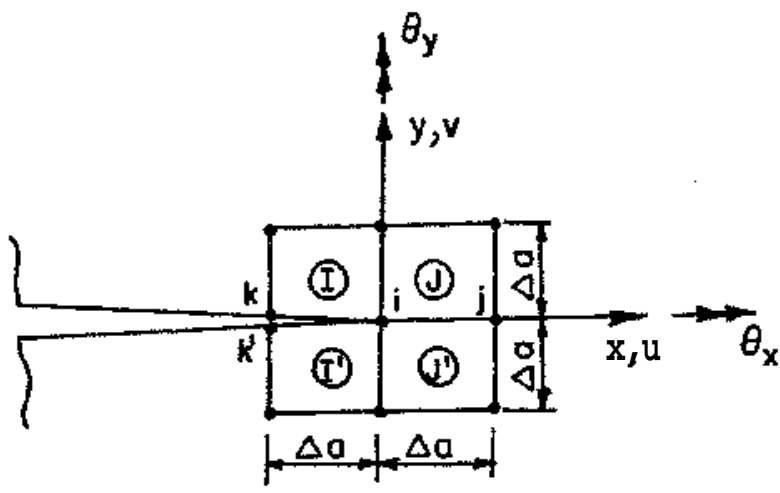

Figure 3. 4 node quadrilatera. elements around a crack tip.

Figure .4. Extrapolation of SIF to crack tip.
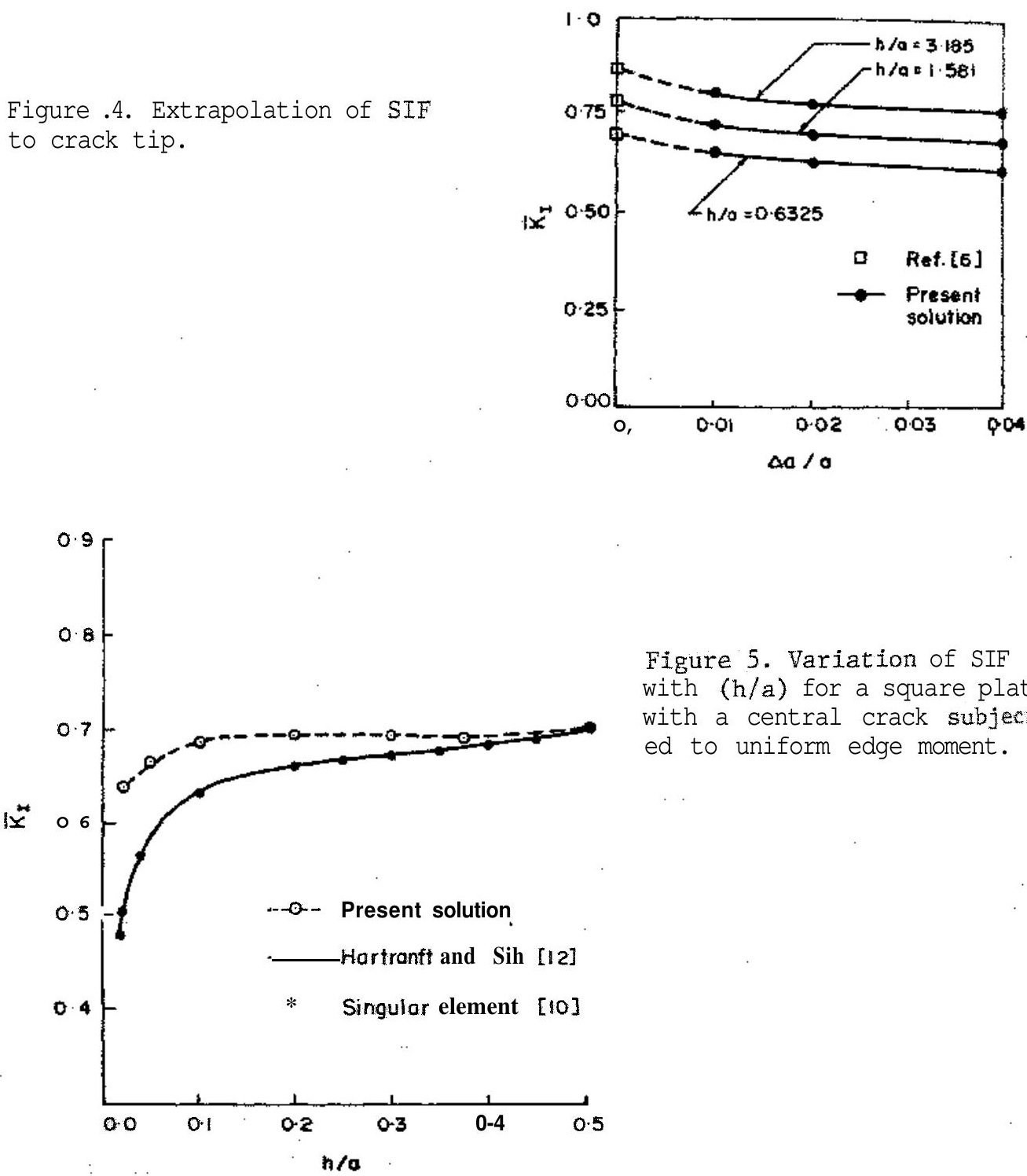

Figure 5. Variation of SIF with $(\mathrm{h} / \mathrm{a})$ for a square plat with a central crack subjec ed to uniform edge moment. 